\title{
Exclusão financeira no Brasil: uma análise regional exploratória
}

\author{
MARCO AURELIO CROCCO \\ FABIANA SANTOS \\ ANA FIGUEIREDO*
}

\begin{abstract}
(20)
Financial exclusion in Brazil: a regional investigation. Despite the fact that after the second half of the nineties the studies of financial exclusion have gained strength among the studies about poverty and regional and social inequalities, a few studies about this problem had appear in the Brazilian economic literature. The present work aims to contribute to this discussion by doing a regional investigation about the phenomenon of financial exclusion inside Brazil. The main hypothesis of the study is that this phenomenon is not disassociated of the space in which it happens. Thought of the use of proxies two dimensions of financial exclusion had been studied: the access to financial services and the suitability of it.

Keywords: Financial exclusion; liquidity preference; banks; regional economics. JEL Classification: G2; R1; E44.
\end{abstract}

\section{INTRODUÇÃO}

A partir da segunda metade dos anos 1990, a discussão acerca do tema exclusão financeira ganhou força nos estudos e pesquisas sobre pobreza e desigualdade social e regional. Acadêmicos, Organizações Não Governamentais, Organismos Multilaterais e Órgãos Governamentais passaram a analisar e desenvolver políticas destinadas a garantir o acesso da população de baixa renda ao sistema financeiro e aos serviços bancários, neste caso em condições compatíveis com suas respectivas

\footnotetext{
* Respectivamente, Professor Titular do Centro de Desenvolvimento e Planejamento Regional, Cedeplar-FACE-UFMG. E-mail: crocco@cedeplar.ufmg.br; Centro de Desenvolvimento e Planejamento Regional-CEDEPLAR. E-mail fabiana@cedeplar.ufmg.br; Pontificia Universidade Católica de Minas Gerais. E-mail lanna@puc.minas.br. Este artigo foi desenvolvido com o apoio financeiro do BNDES através do seu programa PDE/ANPEC/BNDES. Cabe ressaltar que o conteúdo do estudo e pesquisa é de exclusiva responsabilidade dos autores, não refletindo, necessariamente, a opinião do BNDES. Submetido: 12/agosto/2011: Aprovado: 17/outubro/2012.
} 
situações socioeconômicas, de forma que ela possa usufruir de todas as facilidades que tais serviços oferecem.

No Brasil esta discussão, apesar de vir ganhando destaque, ainda é muito incipiente, notadamente no que tange aos esforços de quantificar este fenômeno. $\mathrm{O}$ trabalho mais abrangente já realizado (Kumir, 2004) apresentou evidências contundentes da existência deste fenômeno no Brasil. Embora restrito a uma pesquisa amostral somente para as regiões metropolitanas brasileiras, o estudo mostrou que:

- Apenas $41 \%$ dos entrevistados possuíam conta-corrente.

- $67 \%$ dos que não possuíam gostariam de ter conta-corrente.

- Residentes em áreas formais (regularizadas) possuíam maior acesso à conta bancária com um total de $36 \%$ desta população. Já entre os residentes de áreas informais (tais como favelas) esta proporção foi de $27 \%$ (favelas).

- $46 \%$ dos entrevistados possuíam algum tipo de crédito informal, que vão desde o agiota até empréstimos familiares ou entre amigos, passando pela compra fiada na mercearia.

- Somente $15 \%$ dos entrevistados fizeram algum pedido de crédito formal nos últimos 12 meses, sendo que destes, $2 / 3$ foram aceitos.

- Do total de créditos concedidos, $83 \%$ foram para fins pessoais, sendo $44 \%$ para emergências familiares.

- Do total de entrevistados, apenas $25 \%$ possuíam cartões de débito e $20 \%$ cartões de crédito.

- Finalmente, $68 \%$ dos entrevistados recebiam sua renda principal na forma de dinheiro vivo, $24 \%$ em depósitos em conta-corrente e $4 \%$ em cheques.

Apesar do quadro mostrado acima, são poucas as análises mais abrangentes sobre este fenômeno, como também são limitadas as políticas públicas destinadas a enfrentar o problema da exclusão financeira no Brasil.

O presente trabalho visa contribuir para esta discussão, na medida em que realiza uma análise regional da exclusão financeira, partindo do pressuposto de que ela não é desassociada do espaço onde ocorre. Através do uso de proxies, pretende-se analisar duas dimensões deste fenômeno: a exclusão financeira por acesso e a por serviços.

Além desta introdução, o artigo é composto por três seções. Na primeira, é discutido teoricamente o conceito de exclusão financeira adotado no trabalho. $\mathrm{Na}$ seção seguinte, é realizada uma análise empírica para as grandes regiões do Brasil, a partir da criação de uma série de proxies que tentam captar as duas dimensões do fenômeno mencionadas anteriormente. A relação entre estes indicadores e níveis de pobreza também é analisada. Por fim, considerações finais são feitas na última seção. 


\section{EXCLUSÃO FINANCEIRA: CONSIDERAÇÕES TEÓRICAS}

A discussão sobre o tema exclusão financeira vem ganhando força nos estudos e pesquisas sobre pobreza e desigualdade sociais e regionais. Sua definição assistiu a uma evolução desde o seu surgimento. Segundo Gloukoviezoff (2006, p. 215), a primeira definição de exclusão financeira apareceu com Leyshon e Thrift (1995, p. 314). De acordo com tais autores, exclusão financeira se relaciona a "aqueles processos que servem para prevenir que determinados grupos sociais e individuos tenha acesso ao sistema financeiro".

O que é importante notar é que esta definição, apesar de correta, está relacionada a aspectos físicos e geográficos. Isto, de determinada forma, restringe o conceito a práticas bancárias excludentes, tais como: a localização de agências em áreas com nível de renda mais elevado; e a restrição da oferta de determinados produtos a pessoas de baixa renda ou minoria social, devido aos custos mais elevados de monitoramento. Neste sentido, os estudos sobre exclusão financeira passaram a ampliar o espectro de análise buscando incluir não somente o acesso a serviços financeiros, mas também o seu uso e suas consequências sociais.

Dentro deste contexto, Anderloni et al. (2006) e Gloukoviezoff (2006) afirmam existir duas possibilidades de definições para o termo exclusão financeira. A primeira, mais ampla, seria focada nas necessidades financeiras:

Refere-se às dificuldades vividas por populações de baixa renda em acessar o sistema financeiro em todas suas dimensões de forma a atender a suas demandas. Tais demandas incluem a abertura de conta-corrente, ter a opção de serviços de pagamento sem a utilização de dinheiro e acesso a crédito em condições satisfatórias de pagamento. Estas necessidades também incluem a oportunidade de montar um portfólio modesto de ativo através de veículos apropriados de poupança e investimento que ofereçam termos flexíveis e fácil acesso a fundos, e que também levem em conta benefícios de segurança social e padrões instáveis de trabalho. (Anderloni et al, 2006:7)

A segunda, mais restrita, coloca ênfase em serviços específicos e sua ausência. Estes são usualmente descritos como "essenciais" e referem-se a uma determinada noção de serviços universais, que não impactam o orçamento familiar, mas representam ao mesmo tempo elementos essenciais para a vida das pessoas, subsistência, segurança e participação na vida econômica e social (Anderloni et al., 2006).

De acordo com Anderloni et al. (2006) ${ }^{1}$ são várias as causas e/ou formas de exclusão financeira, a saber:

\footnotetext{
${ }^{1}$ Dentro desta mesma perspectiva existem as classificações de Beck e La Torre (2006) e Honohan (2005). Os dois primeiros autores distinguem três tipos de exclusão: i) limitação geográfica: que seria aquela onde a exclusão ocorreria devido à ausência de agências bancárias ou equivalentes em áreas rurais remotas ou pouco povoadas que são onerosas para a prestação de serviços; ii) limitações socioeconômicas:
} 


\section{Acesso geográfico:}

- Refere-se à existência ou não de agências e/ou postos de atendimento em uma determinada área geográfica.

\section{Exclusão de acesso:}

- Restrição de acesso a serviços bancários resultantes de processos de avaliação de risco por parte dos bancos (custo de avaliação pode ser elevado - redlinning).

\section{Exclusão por condicionantes:}

- Situação onde os condicionantes atrelados a produtos ofertados fazem com que estes não atendam às necessidades de alguns grupos de clientes.

\section{Exclusão por preço:}

- Incapacidade de determinados grupos de indivíduos terem acesso a serviços financeiros, devido ao valor de comissões e/ou tarifas associadas a produtos e serviços.

\section{Exclusão por marketing:}

- Situação onde alguns segmentos do mercado são excluídos pela forma como vendas e publicidades são direcionadas.

\section{Autoexclusão:}

- Situação onde parcela da população se recusa a procurar bancos porque acredita que suas demandas por produtos e serviços serão recusadas.

Este entendimento permite a conceitualização da exclusão financeira que leva em conta tanto o acesso quanto o uso de serviços financeiros. Um aspecto importante destacado por autores como Kempson e Whyley (1999), Caskey e Collard (FSA, 2000) e Gloukoviezoff (2006) é a necessidade de ligar a discussão de exclusão financeira a um fenômeno maior de exclusão social. Para usar o termo de Leyhson e Thrif (1995), poder-se-ia falar em "cidadania financeira". Neste sentido, a exclusão seria uma forma de evitar que pessoas possam fazer uma contribuição econômica para a comunidade (Sinclair, 2001, p. 14).

Assim sendo, pode-se definir o grau de cidadania financeira de um indivíduo de acordo com a intensidade da exclusão financeira sofrida por ele. Em primeiro lugar, estariam aqueles indivíduos que gozam de plena cidadania, possuindo acesso

quando os serviços financeiros se apresentam como inacessíveis para grupos de renda, sociais ou étnicos específicos, quer seja devido a custos elevados, racionamento, analfabetismo financeiro ou discriminação; e iii) limitações de oportunidade: quando iniciantes talentosos com projetos lucrativos recebem negativas de financiamento devido à falta de colateral ou pelo fato de não possuírem as conexões necessárias. Já para Honohan (2005), os fatores determinantes da exclusão financeira seriam: i) barreiras de preço: quando o serviço está disponível, mas a um custo muito elevado; ii) barreiras de informação: quando a reputação de crédito de uma família pobre não pode ser facilmente estabelecida; e iii) design de produtos e serviços: quando os bancos falham em oferecer o tipo de serviço necessário para a população de baixa renda. 
amplo e irrestrito a uma gama enorme de serviços financeiros, compatíveis com a respectiva renda. Tais indivíduos podem utilizar o sistema financeiro de forma a usufruir de toda a potencialidade por ele oferecida, quer seja em termos de preservação e valorização de riqueza, quer seja em termos de acesso a recursos para a realização de oportunidades existentes (Anderloni et al., 2006, Leyshon e Thrift, 1996 e 1997; Menezes e Crocco, 2009).

Neste contexto, poder-se-ia dividir em dois grupos os indivíduos que sofrem exclusão financeira, de acordo com o grau de cidadania financeira a que estão submetidos: ausente ou limitada. No primeiro caso, estariam os "sem banco" (unbanked), que são aqueles que não possuem conta bancária de transação em qualquer instituição bancária formal e/ou aquele que não está, de forma permanente, relacionado a outra pessoa que possui este tipo de conta. No segundo caso estariam os sub-bancarizados (underbanked), que são indivíduos que possuem acesso restrito a serviços bancários (Dymski, 2007; Barr, 2004).

As duas situações anteriores levam tais pessoas a procurarem o mercado financeiro informal, implicando em custos exorbitantes e condições injustas, resultando, em muitos casos, no chamado "sobre-endividamento". Propõe-se, portanto, um entendimento da exclusão financeira de uma forma mais ampla. Ela seria definida em termos das consequências sociais das atividades bancárias. Neste sentido, o sobre-endividamento seria um efeito da forma de atuação dos bancos. Note-se que, no sentido aqui empregado, existe uma grande diferença entre o sobre-endividamento ativo, caracterizado pelo endividamento intencional de um indivíduo acima de sua capacidade de pagamento, no momento da aquisição da dívida, e o sobre-endividamento passivo, caracterizado pela incapacidade de um indivíduo em arcar com pagamento de dívidas, devido a circunstâncias não existentes no presente, como, por exemplo, a ocorrência de desemprego. Esta última situação também é aceita por parte da literatura como uma forma de exclusão financeira, pois está associada à incapacidade dos bancos em lidar com esta nova necessidade (Anderloni et al., 2006; Gloukoviezoff, 2006; Leyshon e Thrift, 1996 e 1997$)^{2}$.

Toda esta discussão sobre tipos de exclusão financeira pode ser sintetizada na Tabela 1.

Tendo em vista a discussão anterior, usaremos neste trabalho a definição proposta por Gloukoviezoff (2004), segundo a qual exclusão financeira é o processo onde pessoas estão excluídas ou encontram dificuldades em suas práticas financeiras de forma que estejam impedidos de usufruir os benefícios que estas práticas propiciam na vida cotidiana. É importante notar aqui que esta definição vai além da discussão sobre o acesso e o uso de serviços financeiros. Incorpora também as

\footnotetext{
${ }^{2}$ Para estudos deste fenômeno nos EUA ver Caskey, J. (1994), Fox, S. (1998), Rhin, S. et al. (2001) e Arthi-Varma (2004). Para o caso do Canadá, ver Buckland, J. et al; (2003) e (2005). Para o caso do Reino Unido, ver Carbó. S. et al. (2005).
} 
consequências sociais, ressaltando que tais consequências sociais variam, dependendo da sociedade em consideração e do status da pessoa em questão.

Tabela 1: Sumário de Diferentes Tipos de Exclusão Financeira

\begin{tabular}{|c|c|c|}
\hline \multicolumn{3}{|l|}{ Dificuldade de Acesso } \\
\hline Práticas do Lado da Oferta & Prospecção Direta & $\begin{array}{l}\text { Políticas Bancárias: recusa em } \\
\text { fornecer serviços devido ao } \\
\text { perfil. }\end{array}$ \\
\hline & Propecção Indireta & $\begin{array}{l}\text { Políticas de localização } \\
\text { de postos e/ou agências } \\
\text { em áreas sem degradação } \\
\text { sócioeconômica. }\end{array}$ \\
\hline Práticas do Lado da Demanda & Autoexclusão & $\begin{array}{l}\text { Recusa em utilizar determina- } \\
\text { dos serviços. }\end{array}$ \\
\hline \multicolumn{3}{|l|}{ Dificuldade de Uso } \\
\hline Práticas do Lado da Oferta & $\begin{array}{l}\text { Perfil do Consumidor avaliado } \\
\text { como "muito custoso para } \\
\text { servir" }\end{array}$ & $\begin{array}{l}\text { Forçar um maior uso de } \\
\text { serviços (pacote de serviços, } \\
\text { ligar um serviço a outro etc.); } \\
\text { Taxas elevadas para aqueles } \\
\text { serviços que são mais } \\
\text { frequentemente utilizados por } \\
\text { consumidores indesejados. }\end{array}$ \\
\hline & $\begin{array}{l}\text { Perfil do Consumidor avaliado } \\
\text { como "muito arriscado para } \\
\text { servir" }\end{array}$ & $\begin{array}{l}\text { Usar cláusulas, taxas e } \\
\text { comissões punitivas para o } \\
\text { não pagamento de forma a } \\
\text { aumentar a lucratividade ou } \\
\text { afastar consumidores não } \\
\text { pagadores; } \\
\text { Beneficiar-se da falta de } \\
\text { conhecimento de clientes } \\
\text { sobre seus direitos. }\end{array}$ \\
\hline Práticas do Lado da Demanda & $\begin{array}{l}\text { Evitar relacionamento } \\
\text { bancário }\end{array}$ & $\begin{array}{l}\text { Não informar ao banco as } \\
\text { dificuldades experimentadas; } \\
\text { Buscar soluções fora do } \\
\text { relacionamento bancário. }\end{array}$ \\
\hline
\end{tabular}

Apud Anderloni et al., 2006.

Uma questão central que se coloca são as razões pelas quais a temática da exclusão financeira ganhou tanto interesse na última década. Várias explicações podem ser levantadas. Anderloni et al. (2006, pp. 12-13) sintetizam seis delas, a saber:

- Interesse mais geral em temas como exclusão e discriminação que estão em voga em vários países, notadamente na União Europeia.

- A padronização de estilos de vida que fazem com que o uso de instrumentos financeiros se torne parte integrante do dia a dia das pessoas. Neste sentido, o não acesso a tais instrumentos torna a vida das pessoas mais difícil, fato este que foi denominado por Servet (2004) como financeirização das relações 
sociais $^{3}$. Além disso, existem características do sistema econômico atual que fazem com que algumas pessoas se coloquem em situações de instabilidade, aumentando assim suas chances de serem excluídas financeiramente. Entre estas características pode-se destacar: i) flexibilização do mercado de trabalho; ii) o desaparecimento da família tradicional, composta por pai, mãe e filho, e o aumento de famílias de um pai ou mãe apenas; iii) o desenvolvimento urbano cada vez mais polarizado, implicando um aumento do gap entre áreas prósperas e pobres; iv) a velocidade do aumento do gap da chamada sociedade do conhecimento (Anderloni et al., 2006, p. 12).

- Estratégias dos bancos que negligenciam pessoas na margem da sociedade. Especialmente, precificação baseada em custos e políticas de risco, com suas correspondentes técnicas de mensuração de lucratividade e alocação de capital, também contribui para este cenário. A pressão sobre os bancos, no sentido de aumento de eficiência (microeconômica), direciona os esforços dos mesmos para o corte de custos. Isto resulta em políticas diferenciadas para os clientes mais abastados, e sem os antigos subsídios cruzados.

- A transformação do sistema financeiro com a privatização ou aquisição, por bancos universais, de tipos de instituições mais aptos a lidar com clientelas mais propícias à exclusão financeira, tais como os bancos mutuais, as cooperativas e os bancos públicos. A principal tarefa destes bancos no passado era desenvolver o contexto local e apoiar as partes mais pobres da população, assim como incentivar o envolvimento da comunidade local.

- Estratégias locacionais dos bancos que negligenciam áreas menos desenvolvidas.

- Crescente afastamento do estado da provisão de segurança social, levando a um aumento da necessidade de poupanças pessoais e ao uso de serviços privados para prover necessidades futuras, incluindo a necessidade daqueles com menor renda.

De forma geral, são observadas, em vários países, três categorias de ação destinadas a lidar com o fenômeno da exclusão financeira, a saber: respostas de mercado; autorregulamentação; e, políticas de governo.

Na categoria "respostas de mercado" estão incluídos os desenvolvimentos espontâneos do próprio sistema financeiro. Uma primeira forma destes desenvolvimentos seria o fornecimento de serviços financeiros destinados aos excluídos por instituições específicas. Neste caso, tais instituições seriam construídas para operarem em áreas especiais para determinadas populações, atuando diretamente para atender às necessidades particulares desta população. Além disso, normalmente são

\footnotetext{
${ }^{3}$ Nas palavras de Gloukoviezoff (2006, p. 222), “a financeirização das relações sociais corresponde ao fato de que as várias conexões que fazem o tecido social (autoestima, ligações com famílias e amigos, ligações com a sociedade como um todo - emprego, consumo) são crescentemente expressas e constrangidas pelo uso de serviços financeiros".
} 
apoiadas por uma rede (para além de sua área de atuação específica) para o suprimento de capacitação e gerenciamento. Exemplos deste tipo de "respostas de mercado" seriam as cooperativas de créditos, Associações Garantidoras de Crédito, Bancos Comunitários, Correspondentes Bancários, entre outros (Anderloni et al., 2006; Leyshon e Thrif, 1996 e 1997). Outra forma de "respostas de mercado" seria o desenvolvimento de serviços direcionados especificamente para segmentos do mercado que exigem necessidades especiais ou possuem dificuldades em acessar o sistema. Finalmente, uma última forma seria a promoção de iniciativas destinadas a ensinar os consumidores a acessar o sistema bancário. Nota-se que esta última forma visa enfrentar apenas um dos aspectos da exclusão, a saber, a desinformação financeira. Ou seja, a exclusão financeira determinada pela falta de educação financeira de alguns setores da população, não se pretendendo, neste caso, enfrentar o problema da exclusão financeira derivada das demais causas e/ou formas de exclusão, como o nível de renda.

Outro tipo de ação de combate à exclusão financeira seria a Autorregulamentação Setorial. Esta é normalmente adotada em resposta à pressão da população ou do próprio governo, consistindo no estabelecimento de normas de conduta e metas de atendimento determinadas pelo próprio sistema financeiro.

Finalmente, o combate à exclusão financeira também tem sido alvo de medidas de intervenção governamental explícita. A experiência internacional tem mostrado duas maneiras de intervenção. Na primeira, o governo atua como facilitador, através de várias medidas, tais como: recomendação de ações para combater exclusão financeira; verificação se produtos bancários atingem ou não o objetivo de redução da exclusão financeira; pressão para a regulamentação e auto avaliação de material de marketing dos bancos pelas agências autorreguladoras. A segunda maneira seria a ação do governo enquanto legislador, criando uma legislação direta que imponha sobre os bancos e outras instituições financeiras a obrigação de fornecer serviços bancários universais (que atendam indiscriminadamente a todas as parcelas da população), ou indireta, destinada a remover obstáculos que reforçam a exclusão financeira (restrições a mobilidade de capital entre regiões; liberação de compulsório para serviços destinados à população excluída etc.). Além disso, a intervenção governamental pode ser feita via incentivos diretos, destinados a motivar o sistema bancário a promover inclusão financeira, tais como: isenção fiscal e garantias oficiais de crédito, dentre outras.

\section{EXCLUSÃO FINANCEIRA NO BRASIL: UMA ANALISE EXPLORATÓRIA}

Mensurar a exclusão financeira no Brasil não é uma tarefa trivial. A escassez de dados dificulta a condução de uma análise mais aprofundada do tema. No entanto, o banco de dados construído pelo Laboratório de Estudos em Moeda e Território (LEMTe) com base nos dados de balanços de agências bancárias por município permite superar parcialmente esta dificuldade, na medida em que permite a construção de proxies que captam o fenômeno da exclusão financeira no país. 
Partindo do entendimento de que os indivíduos possam ser unbanked ou underbanked, como discutido anteriormente, pode-se dizer que a exclusão financeira tenha duas dimensões. A primeira relaciona-se à falta de acesso a uma agência bancária, tomada como proxy da "não bancarização" por acesso. Identificados os municípios sem agência bancária no Brasil (um total de 1.724), os seguintes indicadores nos permitem uma melhor apreensão do fenômeno da exclusão em uma dimensão regional:

1. Total de agências/população: esse índice nos dá o número de agências a cada 100.000 habitantes. Quanto maior este indicador, menor a exclusão financeira por acesso;

2. Proporção de municípios sem agência bancária: representa o percentual de municípios, por região, que não contavam com agência bancária no ano em questão. Quanto maior este indicador, maior a não bancarização.

3. Proporção da população excluída: indica o percentual de habitantes que vivem nas cidades que não possuem agências bancárias. Quanto maior este indicador, maior a exclusão financeira por acesso.

A segunda dimensão, relativa à "sub-bancarização" (ou underbanked), considera que, uma vez que o indivíduo tenha acesso ao sistema bancário (ou seja, possui conta bancária), seu acesso a serviços bancários apropriados é limitado. Para o escopo deste trabalho, foi considerado que Depósitos à Vista e Poupança são os serviços bancários mais básicos, disponíveis para os denominados underbanked (sub-bancarizados). Já as contas Depósito a Prazo e Imposto sobre Operações Financeiras (IOF) captam o acesso a serviços financeiros mais sofisticados e, teoricamente, menos disponíveis para esta categoria de clientes. Baseado neste entendimento, os seguintes indicadores foram definidos visando explicitar a dimensão da sub-bancarização no país, em termos regionais, a partir da proporção de acesso a serviços mais sofisticados em relação ao acesso a serviços básicos:

4. Depósitos a prazo / Depósitos à vista: capta a medida em que o sistema bancário é capaz de transformar seus Depósitos à Vista (produto menos sofisticado) e Depósitos a Prazo (produtos mais sofisticado). Quanto maior este indicador, melhor a adequação dos produtos bancários às características da população da região e menor a exclusão financeira por acesso ou sub-bancarização da região;

\footnotetext{
${ }^{4}$ É importante notar que o fato de existir nas localidades sem agências bancárias correspondentes bancários não compromete a análise realizada, na medida em que se considera que o conceito de exclusão financeira engloba tanto a presença dos estabelecimentos como os serviços por eles prestados. Ademais, o correspondente bancário substitui a agência bancária em um aspecto fundamental na relação cliente-banco, a saber, o contato face a face. Este é de fundamental importância em situações onde parcela significativa da população não possui educação financeira adequada nem tampouco um "credit score" favorável, criando assim condições que incentivam a exclusão financeira. Portanto, os correspondentes bancários não substituem os serviços que podem ser prestados por agências.
} 
5. IOF / Depósitos à vista: capta a mesma dimensão do indicador anterior, porém a proxie de serviços sofisticados é medida pelo total de IOF arrecadado na região. Quanto menor este indicador, maior é a exclusão financeira por acesso. Esta é uma proxy do uso de serviços de intermediação financeira;

6. Poupança / Depósitos a prazo: demonstra a capacidade do sistema bancário em transformar o produto mais básico que oferece (Depósito à Vista) na sua aplicação menos sofisticada (Poupança) $)^{5}$.

\section{Exclusão Financeira por Acesso (Não Bancarização)}

Para entender o comportamento dos indicadores que serão apresentados a seguir é importante ter em mente o processo de reestruturação do setor bancário brasileiro, que teve início no final dos anos 1980 e se estendeu até recentemente. Esse processo foi deflagrado por dois movimentos: um interno e outro externo ao país. O interno diz respeito ao fim do período inflacionário, em meados da década de 1990, que determinou o término do floating - uma das mais importantes fontes de receita dos bancos à época. O externo refere-se à adesão do Brasil às propostas do chamado "Consenso de Washington", que implicou a abertura externa do setor bancário e na sua desregulamentação, aliado ao programa de privatização dos bancos públicos. Esses dois movimentos fizeram com que o sistema bancário brasileiro tivesse de passar por profundo reajuste, tendo sido obrigado a mudar suas estratégias de atuação. Observou-se então um processo de concentração bancária no País, refletindo a concentração geográfica das agências e a onda de fusões e aquisições. Um dos efeitos diretos dessa mudança de postura do sistema bancário foi o aumento da exclusão financeira, com claras diferenças regionais. Em particular, nota-se que nas regiões menos desenvolvidas - Norte e Nordeste - este fenômeno foi mais fortemente sentido ${ }^{6}$.

O Gráfico 1 apresenta a relação do total de agências por 100.000 habitantes, por região brasileira. Observa-se que existe forte discrepância entre a situação existente nas regiões mais desenvolvidas - Sudeste e Sul - e nas menos desenvolvidas - Norte e Nordeste. Nas primeiras, a quantidade de agências por 100.000 habitantes é duas vezes maior do que nas últimas. Pode-se inferir, a partir daí, que

\footnotetext{
${ }^{5}$ Optou-se por separar depósitos à vista de poupança, pois o segundo tem por trás uma ideia de rendimento financeiro e/ou preservação de riqueza, algo que não necessariamente ocorre com depósitos à vista.

${ }^{6}$ Poderia ser argumentado que a disseminação da automação bancária e das tecnologias de informação e comunicação, através do internet banking, seria um dos fatores que influenciariam a evolução no número de agências bancárias. De acordo com dados da Febraban (2009), entre 2000 e 2005 as contas de internet banking triplicaram, saltando de 8,3 milhões para 26,3 milhões. Entretanto, isto não muda o quadro de exclusão financeira antes apontado, na medida em que este serviço depende sobremaneira da renda (capacidade de possuir um computador e arcar com os custos de internet), do nível educacional geral e do nível de educação financeira.
} 
a população destas regiões é mais afetada pela exclusão financeira. A região Centro-Oeste exibe uma situação intermediária.

A apreciação do gráfico permite concluir ainda que, de maneira geral, após o Plano Real, houve uma leve queda no índice, sugerindo ter havido, em um primeiro momento, fechamento de agências. A partir de 1999-2000, a quantidade de agências por 100.000 habitantes permaneceu relativamente estável, não obstante a região Sudeste apresentar certa oscilação ao longo dos anos. A região Centro-Oeste, por sua vez, se destaca pela redução mais acentuada na variável: chegou a contar com 13 agências por 100.000 habitantes em 1995, passando para 9 em 2008.

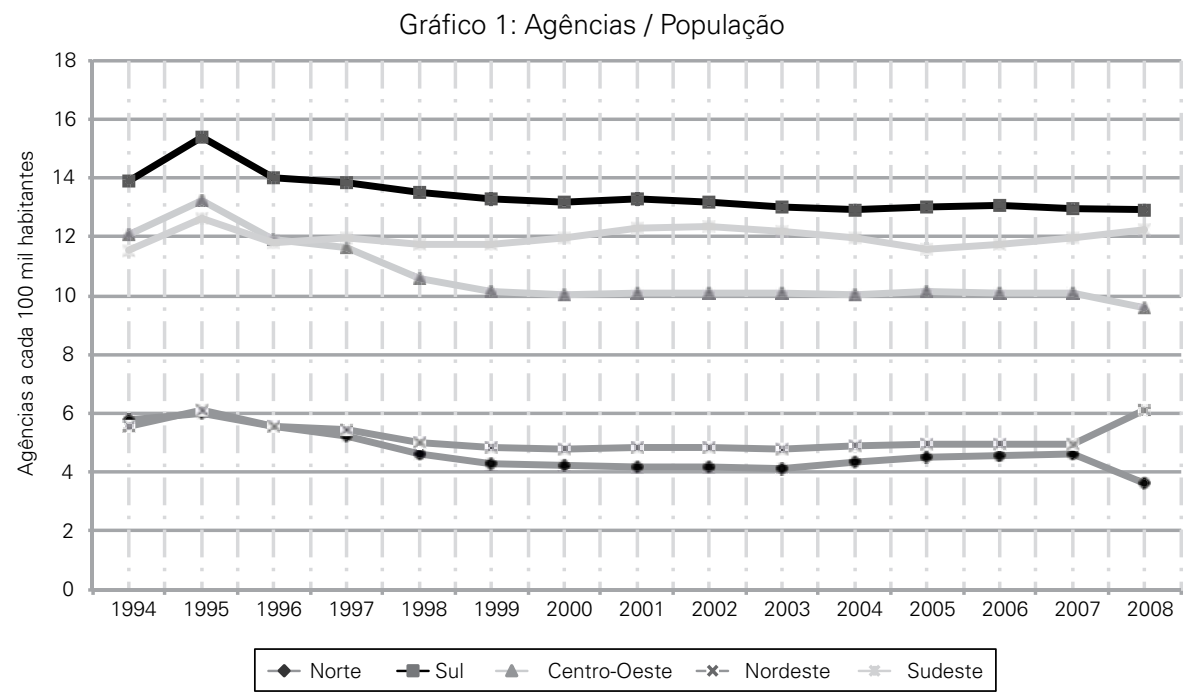

Analisando este indicador em conjunto com os contidos nos Gráficos 2 e 3, pode-se constatar que, após o ajustamento pós-Plano Real, a relativa estabilidade no número de agências e a busca de ganhos de escala levaram à relocalização de agências para regiões de maior renda e maiores economias de aglomeração e urbanização. De fato, pelo Gráfico 2 percebe-se que nas regiões Sul e Sudeste não houve muita variação no percentual de municípios sem agência bancária, nos primeiros anos de estabilização. Já no Norte e Nordeste, verificou-se significativo aumento da proporção de municípios sem agências — especialmente entre 1997 e 2003 — e, obviamente, também da população não atendida (Gráfico 3). No Centro-Oeste, a variação também foi relevante. Em outras palavras, pode-se inferir que os bancos, como resposta ao novo cenário macroeconômico - redução drástica da inflação e desregulamentação do setor bancário -, optaram por fechar agências nas localidades mais pobres, privilegiando as áreas mais ricas. Como resultado, a exclusão financeira foi ampliada nas regiões mais pobres. Em 1995, 16,5\% da população nortista não tinha acesso a agências bancárias, por morar em um dos $59 \%$ de municípios que não dispunham desse serviço. Em 2001, o percentual saltou para $24,9 \%$ e ampliou-se para $68,7 \%$ a quantidade de municípios desassistidos. No 
Nordeste, a situação é bastante semelhante. Em 1995, 14,3\% das pessoas sofriam de exclusão financeira. Elas residiam em um dos 50\% de municípios sem agências bancárias. Em 2001, já eram quase $60 \%$ as cidades que não contavam com agências, afetando $21,7 \%$ da população.

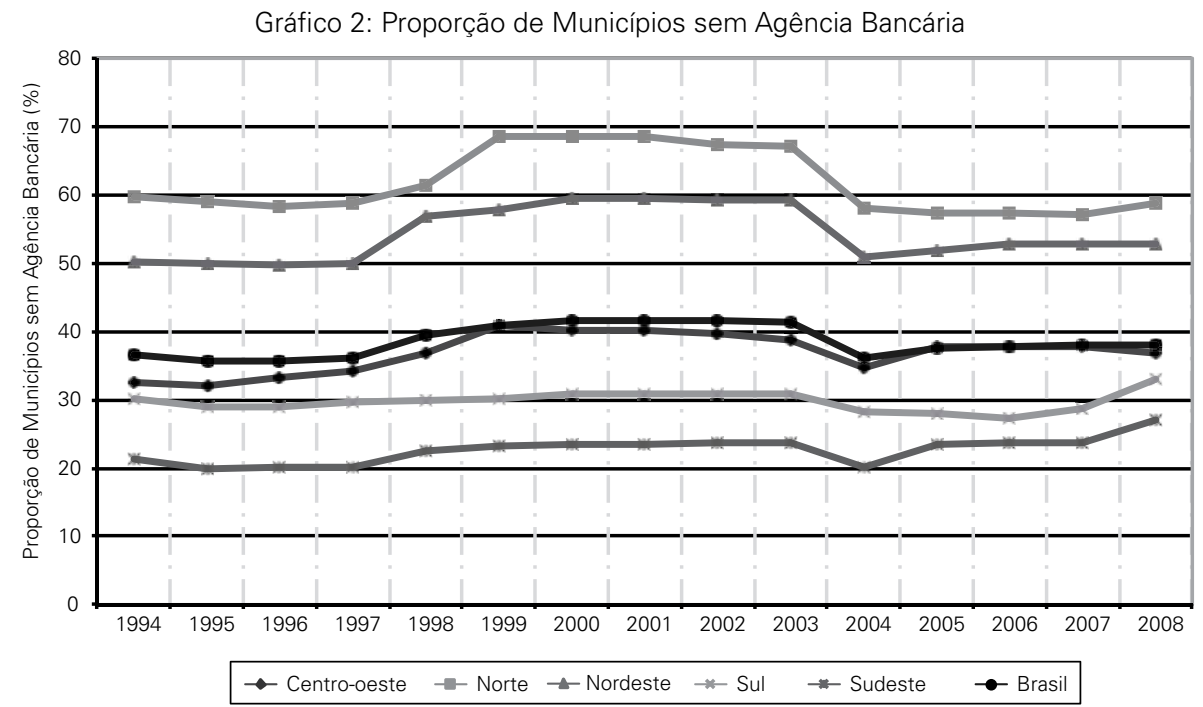

A análise dos gráficos também evidencia a ocorrência de uma redução da exclusão financeira a partir de 2003, especialmente nas regiões Norte, Nordeste e Centro-Oeste ${ }^{7}$. O período coincide com a mudança de governo e o início do primeiro mandato do presidente Lula. A estratégia dos bancos no período pode ter sido a de promover a ampliação do acesso bancário à população (via abertura de agências), de forma a aumentar a participação do segmento de varejo nas suas atividades. Com isso, buscavam tirar proveito da elevação observada na renda da população a partir de $2003^{8}$. De fato, tal segmento teve forte expansão, apesar dos altos spreads cobrados pelos bancos.

Contrastando com o quadro de forte exclusão financeira que se apresenta nas regiões Norte e Nordeste, no Sul e Sudeste, observa-se um percentual relativamente pequeno de pessoas excluídas financeiramente - ainda que uma proporção significativa de cidades não disponha de agências bancárias. Tal fato pode ser comprovado pela análise dos Gráficos 2 e 3, que sugerem que uma parcela reduzida da população vive nas cidades desprovidas de agências bancárias. Assim, por exemplo,

\footnotetext{
${ }^{7}$ Entretanto, não se chegou, em 2008, aos níveis registrados em 1995.

${ }^{8}$ A ampliação da renda, especialmente nas camadas mais pobres da população, esteve ancorada no programa de transferência direta de renda do governo, chamado "Bolsa Família". Além disso, de acordo com dados do IBGE, entre 2003 e 2009 a renda média do trabalhador aumentou 14,3\% nas seis principais regiões metropolitanas, e a população ocupada também foi ampliada em $14 \%$.
} 
no Sudeste, em 1995, apenas $1,71 \%$ das pessoas da região viviam em tais municípios. Ao passo que, neste mesmo ano, eram quase $20 \%$ as cidades que não possuíam este serviço. Ao longo dos anos, observa-se uma pequena elevação nesses percentuais. Em 2008, os municípios sem agência na região atingiram aproximadamente $2,5 \%$ e a população vivendo nessas cidades, $27 \%$.

Por fim, no Centro-Oeste, $32 \%$ dos municípios não contavam com agências bancárias em 1995. Entretanto, somente 4,5\% da população da região residia nestes municípios. Ao longo dos anos observou-se aumento em ambos os percentuais, que atingiram o ápice em 2001, com, respectivamente, 40,3\% e 9,6\%. O comportamento dos indicadores registrados nesta região se assemelha ao dos índices calculados para o Norte e o Nordeste. Entretanto, cabe ressaltar que aqui o grau de exclusão financeira é significativamente menor.

Em suma, os três indicadores analisados mostram que houve um processo geral no Brasil de fechamento de agências, ampliando a exclusão financeira, a partir de 1995, que perdurou até 2003. Mesmo havendo melhora na acessibilidade a agências bancárias a partir de 2003, a exclusão financeira de parcela significativa da população se manteve, não se repetindo a situação prévia ao Plano Real. Com visto, este movimento foi particularmente forte nas regiões menos desenvolvidas - Norte e Nordeste. Fica claro, assim, que a estratégia diferenciada dos bancos no território leva a diferenças regionais no fenômeno da exclusão, contribuindo para a perpetuação das disparidades regionais brasileiras.

Gráfico 3: Proporção da População Excluída

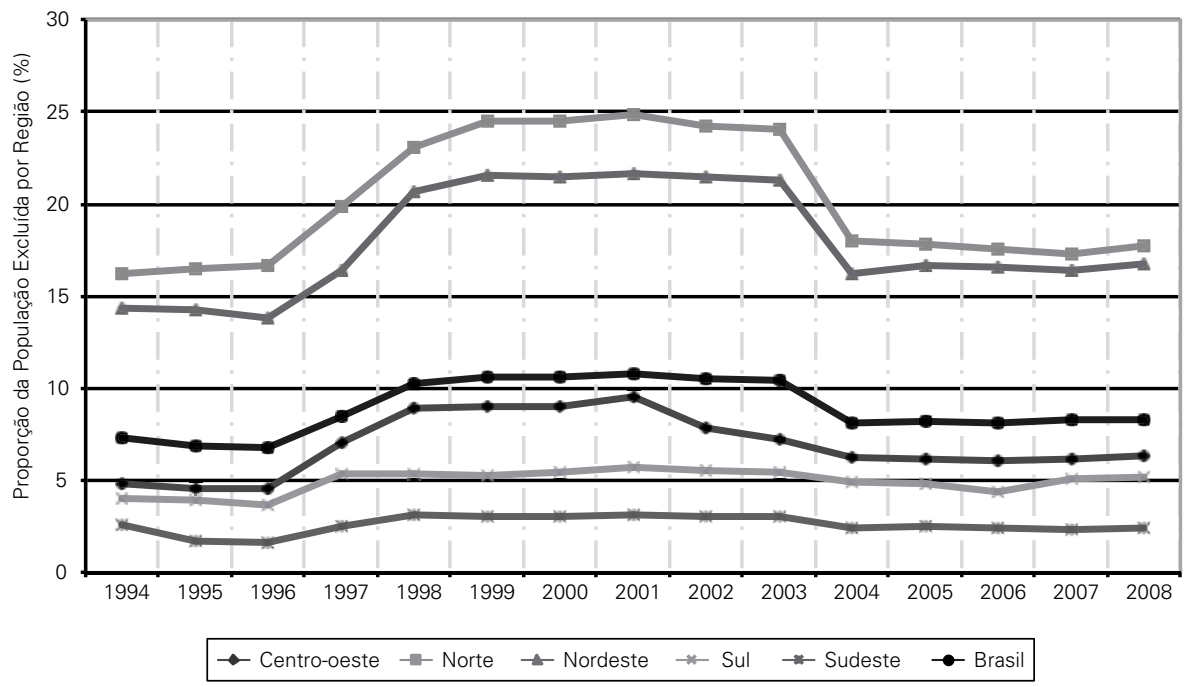

O arcabouço teórico pós-keynesiano fornece uma explicação para a existência de diferenças regionais na exclusão financeira. Segundo esta escola, as regiões gozam de preferências pela liquidez distintas, em função dos diferentes níveis de incerteza local, associados às expectativas sobre os retornos dos ativos financeiros e 
reais. Tal fato determina um padrão diferenciado de oferta de serviços bancários. Esta tende a ser restringida em regiões menos desenvolvidas, menos diversificadas economicamente e de menor renda, o que, por sua vez, influencia o desenvolvimento regional (Dow, 1982 e 1993; Rodríguez-Fuentes, 1998). Em suas estratégias de localização de agências bancárias, os bancos privilegiam a magnitude da renda e a escala local. Assim, ao considerar o fechamento de agências, os bancos tenderão a fazê-lo nas áreas menos prósperas e menos diversificadas, mais sujeitas a volatilidade de renda e emprego. Por sua vez, nas áreas de economias mais diversificadas, menos sujeitas a incertezas, menor é a probabilidade de variação no número de agências. De fato, conforme demonstrado anteriormente, nas regiões Sul e Sudeste observou-se um padrão muito mais estável da exclusão financeira nos anos pesquisados. Ao passo que o Norte, o Nordeste e o Centro-Oeste sofreram maior oscilação na variável.

\section{Exclusão Financeira por Serviços (Sub-Bancarização)}

Procura-se agora analisar a exclusão financeira a partir da acessibilidade a serviços financeiros mais sofisticados.

O Gráfico 4 mostra a evolução do primeiro indicador que busca capturar esta dimensão9, qual seja, Depósitos a Prazo/Depósitos à Vista. O primeiro aspecto que chama a atenção é o fato de que, em quase todo o período, este indicador apresentou os maiores valores para a região Sudeste e os menores para a região Nordeste. Ou seja, pode-se afirmar que as agências bancárias localizadas nas regiões mais desenvolvidas forneceram aos seus clientes serviços bancários mais sofisticados, enquanto o mesmo não ocorreu nas regiões menos desenvolvidas do Norte e Nordeste. Nesta última, o pequeno valor do indicador é uma evidência do fato de o setor bancário não ofertar modalidades de aplicações financeiras compatíveis com as características de seus clientes.

A análise da dinâmica temporal deste indicador também mostra características interessantes. Em primeiro lugar, observa-se uma redução da variável entre o período 1995 e 1997. Este fato ocorre de forma generalizada em todas as regiões, e pode ser explicado pelo fim do processo inflacionário, que reduziu a rentabilidade (nominal) de várias aplicações capturadas na conta Depósitos a Prazo, notadamente aquelas indexadas à variação do IGP-M. Vale salientar que, apesar desta tendência ser generalizada entre as regiões, sua intensidade é claramente diferenciada. As regiões mais desenvolvidas apresentaram uma queda mais significativa, indicando que o acesso a serviços financeiros indexados no período inflacionário também era diferenciado regionalmente, com maior exclusão em regiões mais pobres.

\footnotetext{
${ }^{9}$ A região Centro-Oeste foi excluída desta análise, pois no seu interior encontra-se a capital do país, Brasília. Por razões políticas, nesta cidade encontram-se as sedes de dois grandes bancos públicos (Banco do Brasil e Caixa Econômica Federal) e neles estão alocadas as contas da administração central do pais. Este fato faz com que os valores das variáveis aqui analisadas sofram a influência de fatores não econômicos. Por esta razão, optou-se por não analisar a referida região.
} 


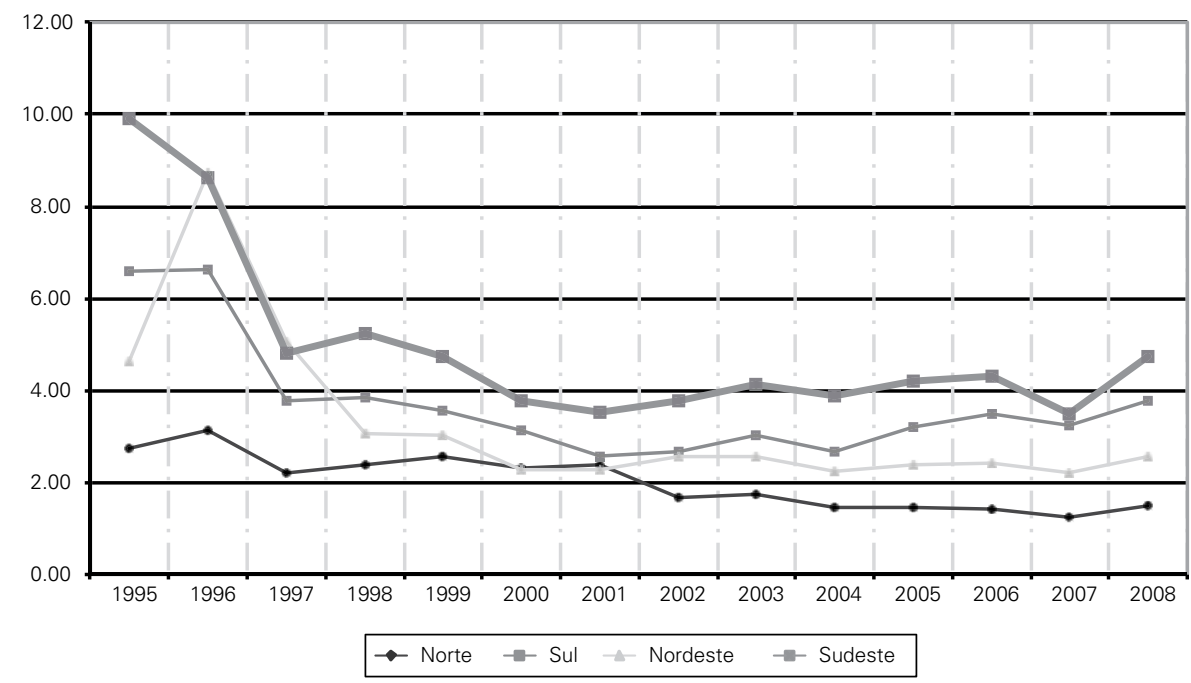

Após 1997 passam a existir diferenças regionais. A região Norte reverte a tendência de queda, que perdura até 2002. As demais regiões, por sua vez, continuam com a redução deste indicador até o ano de 2001. Vale salientar que o período entre 1995 e 2001 foi caracterizado por uma redução sistemática da taxa anual média de juros (com exceção para o ano de 1998). Este fato explicaria a tendência de queda na variável. Do ponto de vista regional, o que é importante destacar é que este movimento tende a amenizar as diferenças regionais, indicando que este tipo de exclusão financeira é mais intensa quanto maior for a taxa de juros. Ou seja, com os juros mais elevados, o sistema bancário tenderia a ofertar maior quantidade de serviços financeiros para as regiões mais desenvolvidas, ampliando, desta forma, a exclusão financeira (relativa) em regiões menos desenvolvidas.

Vale ressaltar que o sistema bancário brasileiro é caracterizado por bancos nacionais com agências espalhadas pelo país. Este tipo de estrutura tende a incentivar e a facilitar o processo de homogeneização dos produtos oferecidos por tais instituições. Ou seja, estes produtos são similares em todo o território, não se adequando às características de cada região. Além disso, normalmente tais produtos são padronizados tendo em vista o perfil socioeconômico das regiões mais desenvolvidas. É este comportamento que faz com que o indicador seja pequeno em regiões menos desenvolvidas, significando níveis mais elevados de exclusão financeira em regiões menos desenvolvidas.

Após 2002, o comportamento regional diferenciado se cristaliza. Enquanto as regiões Norte e Nordeste mostraram uma tendência de leve redução do indicador - sugerindo um aumento da exclusão financeira —, as regiões Sul e Sudeste apresentaram um significativo aumento na variável, ou, dito de outra forma, uma redução da exclusão financeira. Este quadro se mantém até 2007. Em 2008, entretanto, todas as regiões aumentaram o valor deste indicador. 
Comportamento similar é observado quando se analisa a relação entre o valor do IOF arrecadado em uma região com o valor dos Depósitos à Vista. Como dito anteriormente, este indicador tenta captar o quanto o sistema bancário em uma região consegue oferecer de produtos financeiros, em relação ao volume de seus Depósitos à Vista. Como mostra o Gráfico 5, este indicador foi maior para regiões mais desenvolvidas, durante todo o período analisado, sugerindo menor exclusão financeira nestas regiões. Além disso, e de forma similar ao indicador anterior, com o fim do processo inflacionário ocorre uma diminuição desta variável para todas as regiões, até o ano 2000. A partir daí, verifica-se uma estabilidade desta relação até 2008 , onde, de forma generalizada, ocorre um brusco aumento. Vale lembrar que este último ano foi caracterizado pela crise financeira mundial.

O que esta última observação mostra é que em ambientes macroeconômicos com forte conteúdo de incerteza - como foi o caso tanto do período inflacionário, quanto da crise - existe uma tendência do sistema bancário em aumentar a intensidade da sub-bancarização - representando um comportamento de aversão ao risco e represamento de liquidez. É o que mostram tanto a evolução da relação Depósitos a Prazo sobre Depósitos à Vista, quanto da relação total arrecadado com o Imposto sobre Operações Financeiras (IOF) sobre Depósitos à Vista. Ou seja, neste cenário, o sistema bancário não fornece produtos que atendam às necessidades de consumidores de menor renda. Isto explicaria o aumento destes dois indicadores nas regiões mais desenvolvidas.

Gráfico 5: IOF / Depósitos à Vista

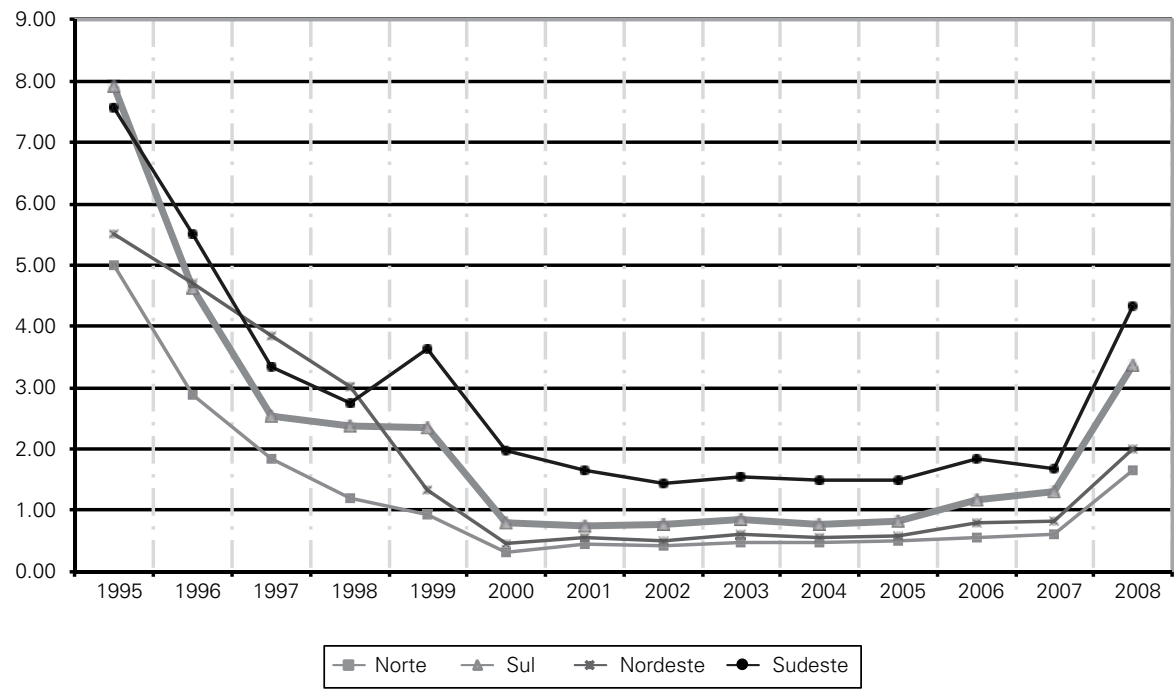

Antes de prosseguir, faz-se necessário um esclarecimento. Tem-se claro que os fatores renda e escala possam ter influenciado os resultados acima mostrados. $\mathrm{Ou}$ seja, a região Sudeste apresentaria maiores valores, pois, como sua renda é maior, então maior quantidade de recursos estaria disponível para aplicações financeiras. 
Embora este argumento deva ser considerado, na presente análise, os indicadores são ponderados pelos Depósitos à Vista. Assim sendo, se os produtos oferecidos pelos bancos fossem moldados para cada tipo de cliente, as relações acima deveriam ser similares em todas as regiões. Ou seja, os volumes de Depósitos a Prazo e IOF seriam proporcionais ao volume de Depósitos à Vista, que, por sua vez, seria proporcional à renda da região. Isto ocorrendo, os indicadores das diversas regiões tenderiam à convergência. Como isto não acontece, parece então que a renda não é o fator determinante para explicar os resultados obtidos. A hipótese aqui defendida é que tais resultados são fruto de estratégias deliberadas por parte dos bancos, levando a níveis bastante distintos de sub-bancarização. Dentre tais estratégias a mais comum seria a recusa dos bancos em fornecer produtos não padronizados à clientes de baixa renda, preferindo ofertar produtos padronizados tendo como parâmetro consumidores de mais alta renda, típico de regiões mais desenvolvidas.

Dois outros indicadores são utilizados para captar o fenômeno da exclusão financeira por serviço, ambos tendo como referência o volume de poupança da região. Como se sabe, a poupança se caracteriza, no Brasil, por ser a aplicação financeira mais acessível à população de todas as classes de renda. De forma semelhante aos Depósitos à Vista, a Poupança é aqui considerada como a aplicação financeira mais básica, dentre tantas do setor bancário. Assim, ao se comparar Depósitos a Prazo com o total de Poupança, pretende-se obter uma proxy da exclusão por serviço. Nesse caso, quanto maior este indicador menor a sub-bancarização, sugerindo um maior acesso dos consumidores de uma região específica a outras aplicações além da Poupança. O Gráfico 6 mostra os resultados obtidos.

Gráfico 6: Depóstos a Prazo / Poupança

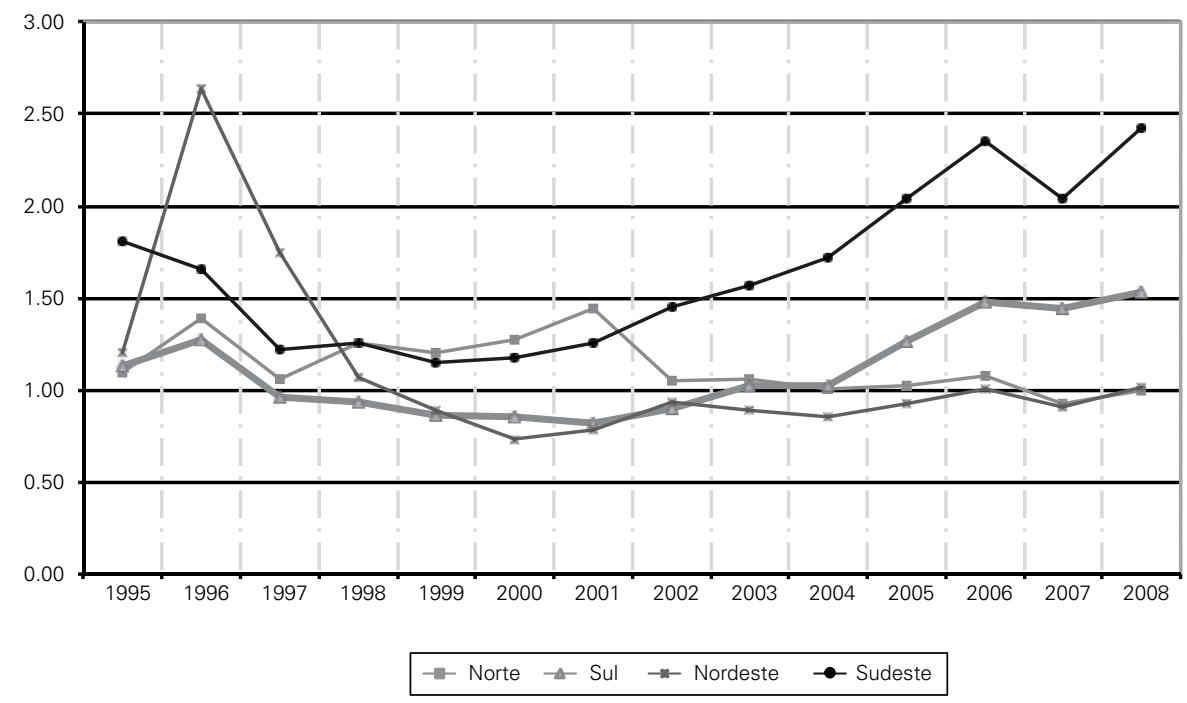

As diferenças regionais mais uma vez se fazem presentes. A região Sudeste, confirmando os indicadores anteriores, apresentou o menor grau de sub-bancari- 
zação em quase todo o período de análise, sugerindo claramente que os clientes das agências bancárias situadas nesta região possuem alternativas de aplicação financeiras que combinam com suas características e necessidades. A região Sul, apesar de apresentar patamares bem distintos aos observados para a região Sudeste, mostra um comportamento similar a esta. Em ambos os casos, a variável apresenta um crescimento constante pós-2000.

Já as regiões Norte e Nordeste apresentam um comportamento claramente distinto, apresentando valores que tendem a diminuir em um primeiro momento e a se estabilizar em outro. Além disso, em valores absolutos, tendem a convergir a um mesmo patamar, em torno de 1 . Ou seja, um volume de Depósitos a Prazo igual ao volume de Poupança. Fica evidente, mais uma vez, a exclusão financeira por serviços em regiões menos desenvolvidas.

Finalmente, o último indicador a corroborar os resultados apresentados é a relação entre Poupança e Depósitos à Vista. Como se trata dos dois produtos bancários mais básicos, é de esperar que ele apresente valores maiores para as regiões onde a sub-bancarização seja maior, pois nestas a Poupança seria o produto que melhor se adequaria às características socioeconômicas destas regiões. O Gráfico 7 mostra os resultados obtidos.

Um padrão geral é observado claramente: a redução do valor deste indicador, para todas as regiões, no período analisado. Uma explicação para o fato seria o processo de transformação por que passou o sistema bancário brasileiro, durante os anos 1990, com um aumento do denominado financial deepening (aprofundamento financeiro), aqui entendido como o processo de diversificação de produtos financeiros. Isto faz com que, de forma geral, surjam alternativas de aplicação financeira à Poupança, determinando assim a redução do indicador durante todo o período.

Chama a atenção, contudo, o diferencial de intensidade com que este processo ocorreu entre as regiões analisadas. Como mostra o gráfico, imediatamente após o fim do período de hiperinflação as regiões Sudeste e Sul apresentavam o maior valor para este indicador. Com o passar da segunda metade dos anos 1990, tais regiões apresentaram uma queda significativa na variável, fazendo com que, já a partir de 2001, começassem a ser superadas pela região Nordeste. Este fato pode indicar que o processo de diversificação e inovação financeira não é homogêneo no espaço, estando primordialmente circunscrito às regiões mais desenvolvidas. Dito de outra forma, este processo, ao ocorrer com intensidades distintas no território, aprofundou o crescimento do fenômeno da exclusão financeira por serviços.

Por fim, cabe notar a evolução deste indicador nas regiões Norte e Nordeste. $\mathrm{O}$ resultado fortalece o argumento de que as condições regionais são determinantes na atuação do sistema bancário, que reforça o fenômeno da exclusão financeira. Como mostra o gráfico, a partir de 2003 a região Nordeste apresenta o maior valor para este indicador, como previsto pela teoria.

Vale ressaltar o fato de a região Norte ter apresentado o menor valor durante todo o período, contrariamente ao esperado. A explicação poderia ser a escala e a renda local. No entanto, isso merece uma análise mais detalhada que foge ao escopo deste trabalho. 
Gráfico: Poupança / Depósitos à Vista

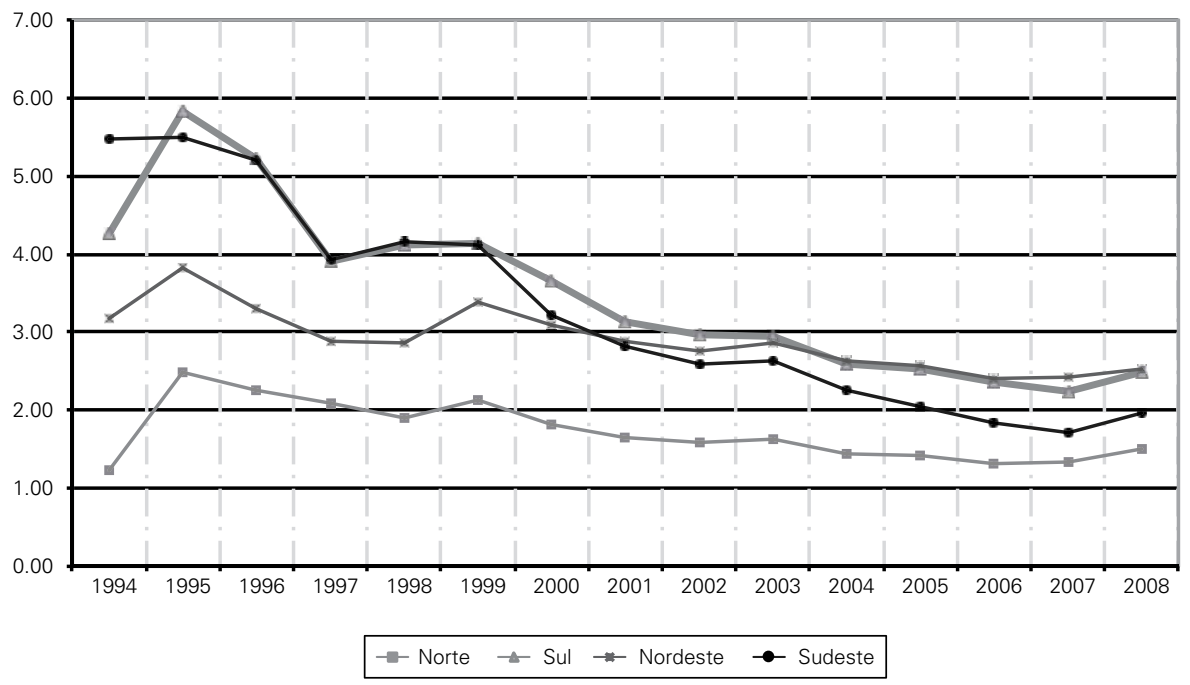

\section{Exclusão Financeira e Pobreza}

Embora a mensuração do grau de exclusão financeira seja, por si só, extremamente relevante, a análise anterior não estaria completa se não fosse considerada a sua relação com a pobreza ${ }^{10}$. Isso significa analisar a exclusão financeira como um importante componente e, em certos casos, um determinante da exclusão social. Obviamente, este é um tema que, por si só, mereceria um estudo específico. No entanto, ainda que de forma preliminar, algumas conclusões podem ser tiradas através de um exercício simples de correlação. Isto é feito a seguir, com os resultados apresentados na Tabela 2 .

Foram analisados três anos do período em estudo. Cada um relacionado a um ambiente macroeconômico distinto: em 1995, o país vivenciava o fim da era inflacionária; em 2001, o fim da ilusão da paridade cambial; e, em 2008, a crise financeira mundial, após um período de crescimento robusto. Além disso, correlacionou-se o indicador de pobreza com os indicadores tanto de exclusão financeira de acesso (Agências/População), quanto de exclusão financeira de serviço (IOF/DV; DP/DV e Poup/DV).

\footnotetext{
${ }^{10}$ Utiliza-se aqui o indicador "Taxa de pobreza", fornecido pelo IPEADATA. De acordo com este órgão, taxa de probreza refere-se ao "percentual de pessoas na população total com renda domiciliar per capita inferior à linha de pobreza. A linha de pobreza aqui considerada é o dobro da linha de extrema pobreza, uma estimativa do valor de uma cesta de alimentos com o mínimo de calorias necessárias para suprir adequadamente uma pessoa, com base em recomendações da FAO e da OMS” (http://www. ipeadata.gov.br).
} 
Tabela 2: Índices de Correlação entre Pobreza

e Indicadores de Exclusão Financeira

\begin{tabular}{|l|c|c|c|c|}
\hline & & 1995 & 2001 & 2008 \\
\hline IOF/DV & Pearson Correlation & -0.475 & -0.733 & -0.625 \\
\hline & Sig. (2 tailed) & 0.419 & 0.159 & 0.26 \\
\hline DP/DV & N & 5 & 5 & 5 \\
\hline & Pearson Correlation & -0.555 & -0.743 & -0.824 \\
\hline & Sig. (2 tailed) & 0.332 & 0.15 & 0.087 \\
\hline POUP/DV & $N$ & 5 & 5 & 5 \\
\hline & Pearson Correlation & -0.362 & 0.058 & 0.279 \\
\hline & Sig. (2 tailed) & 0.549 & 0.926 & 0.649 \\
\hline Agpop07 & $N$ & 5 & 5 & 5 \\
\hline & Pearson Correlation & -0.869 &,$- 902\left(^{*}\right)$ &,$- 939\left(^{*}\right)$ \\
\hline & Sig. (2 tailed) & 0.056 & 0.037 & 0.018 \\
\hline & $N$ & 5 & 5 & 5 \\
\hline
\end{tabular}

* Correlation is significant at the 0,05 level (2-tailed).

** Correlation is significant at the 0,01 level (2-tailed).

Os resultados sugerem que a exclusão financeira por acesso (Agpop07) se correlaciona diretamente com a pobreza. Ou seja, ter acesso a uma agência bancária, e poder conversar e se informar com um gerente - isto é, o contato face a face - é é fundamental para a inclusão financeira e, portanto, para que o indivíduo tenha acesso a serviços bancários que possam vir a reduzir a sua exclusão social, como, por exemplo, no caso de acesso ao crédito. Além disso, ressalte-se que este indicador apresentou o maior coeficiente de correlação entre os analisados.

Apesar dos demais índices não terem apresentado correlações significativas, alguns comentários podem ser feitos. Em primeiro lugar, a análise dos sinais. Como mostra a tabela, as variáveis IOF/DV e DP/DV registraram, em todos os anos analisados, sinal negativo. Ou seja, um aumento destes indicadores está positivamente relacionado com a redução da pobreza. Assim, um aumento do acesso a serviços financeiros mais sofisticados pode contribuir para reduzir os indicadores de pobreza. Além disso, vale ressaltar que no caso do indicador DP/DV o coeficiente de correlação aumenta a cada ano analisado.

\section{CONSIDERAÇÕES FINAIS}

O presente estudo constitui-se em um trabalho exploratório, que busca analisar duas dimensões da exclusão financeira, a saber, a exclusão por acesso e a exclusão por serviços, sob a ótica regional. Ele vem preencher uma lacuna na literatura econômica brasileira, onde são poucos os trabalhos que tratam sobre o tema da exclusão financeira de maneira mais geral e onde são ainda mais raros os trabalhos que a abordam em uma perspectiva regional. 
A grande dificuldade enfrentada pelos estudiosos do tema é a disponibilidade de dados para substanciar suas análises. De fato, a maioria dos estudos sobre exclusão financeira acaba tendo que recorrer a pesquisas primárias para superar tal obstáculo. Informações também sobre as negativas de crédito e diferenciais dos custos dos serviços por cliente são praticamente impossíveis de obter. Nesse caso, o recurso a proxies das variáveis centrais acaba sendo necessário, como realizado nesse trabalho.

Um outro aspecto que merece ser destacado é que o tema da "bancarização" vem sendo tratado de maneira agregada (vide os estudos da Febraban) o que, na verdade, mascara as grandes disparidades inter-regionais da inclusão financeira no Brasil, como foi visto neste estudo.

Isso explicita a importância e o ineditismo do esforço do LEMTe (Laboratório de Estudos sobre Moeda e Território) na construção do banco de dados financeiros regionais.

Os resultados obtidos nesta investigação apontam claramente para a existência de exclusão financeira, com recortes regionais visíveis. Como mostrado, tanto os indicadores de exclusão por acesso, quanto os de exclusão por serviços sugerem que nas regiões menos desenvolvidas a intensidade deste fenômeno é superior à observada em regiões mais desenvolvidas. Este resultado evidencia o fato de a exclusão financeira ter um componente territorial marcante.

Os dados apresentados mostraram um sistema bancário incapaz não somente de atender ao território de forma equilibrada, o que determina a ocorrência da exclusão financeira por acesso, mas também de fornecer produtos que se adequem às características especificas do território onde atua (exclusão financeira por serviço). Ou seja, os produtos bancários são homogêneos, gerando a sub-bancarização para aqueles que não se enquadram no perfil previsto.

Este fato coloca a exclusão financeira em um patamar similar ao de outras formas de exclusão. Isto reforça a necessidade de considerar este fenômeno não apenas como um problema de ineficiência do sistema bancário, gerado por assimetrias de informação e custos de transação, mas sim um fenômeno mais geral de exclusão social, onde a postura adotada pelo sistema bancário é mais um componente em uma dinâmica mais geral. No presente trabalho, foi explorada uma faceta desta dinâmica: suas características regionais. Outras dimensões devem ser analisadas em pesquisas posteriores.

\section{REFERÊNCIAS BIBLIOGRÁFICAS}

AMADO, A. Questão regional e o sistema financeiro no Brasil: uma interpretação pós-keynesiana, Estudos Econômicos, vol. 27, n.3, p. 417-440, set-dez., 1997.

ANDERLONI, L. et al. New Frontiers in Banking Services: emerging needs and tailored products for untapped markets, Nova York, Springer, 2006.

ANDERLONI, L. et al. Access to bank accounts and payment services, em ANDERLONI, L. et al. (ed) New Frontiers in Banking Services: emerging needs and tailored products for untapped markets, Nova York, Springer, 2006. 
ARTHI VARMA. A survey of check cashers in the San Francisco Valley, Valley Economic Development Center, December, 2004.

BARR, M. Banking the poor, Yale Journal on Regulation, vol. 21, p. 121 -237, Winter, 2004.

BUCKLAND, J. et al. Fringe Banking in Winnipeg's North End, Canadian Center for Policy Alternatives, Ottawa, 2005.

CARBÓ, S. et al. Cajas de ahorros, tecnologia e inclusion financeira, Cuadernos de Información Económica, n. 188, septiembre-octubre, pp. 105-12, 2005.

CASKEY, J. Fringe Banking: check-cashing outlets, pawshops, and the poor, Russel Sage Foundation, New York, 1994.

CROCCO, M. et al. The behaviour of liquidity preference of banks and public and regional development: the case of Brazil. Journal of Post Keynesian Economics, Nova York, v. 28, n. 2, p. 217-240, 2005.

DOW, S. The regional composition of the money multiplier process. Scottish Journal of Political Economy. v. 19, n.1, 1982.

DOW, S.C. Stages of Banking Development and the Spatial Development of Financial Systems. in MARTIN, R. (ed.). Money and the Space Economy. Wiley, p. 31-48, 1999.

DYMSKI, G. Exclusão e eficiência: a transformação global do core banking, um estudo para o Brasil, em De Paula, L. F. e Oreiro, J. (Org.) Sistema Financeiro: em análise do setor bancário brasileiro. Rio de Janeiro, Elsenier, 2007.

FOX, C. The Growth of Legal Loan Sharking: a report on the payday loan industry, Consumer Federation of America, 1998.

GLOUKOVIEZOFF, G. De la bancarisation de masse à l'exclusion bancaire puis sociale, Revue Française des Affairs Sociales, n. 3, pp. 15-29, 2004.

GLOUKOVIEZOFF, G. From financial exclusion to overindebtedness: the paradox of difficulties of people on low incomes, in Anderloni, L. et.al. (ed) New Frontiers in Banking Services: emerging needs and tailored products for untapped markets, Nova York, Springer, 2006.

GOLDSMITH, R.W. Financial Structure and Development, New Haven, Yale University Press, 1969.

KEMPSON, E. et al. In or out?, Financial exclusion: a literature and research review, Consumer Research, FSA, n.3, July, 2000.

KEMPSON, E. et al. Kept in or opted out? Understanding and combating financial exclusion, Bristol, Policy Press, 1999.

KEMPSON, E. et al. The Rise of Fringe Financial Services in Winnipeg's North End: clients experience, firm legitimacy and community-basel alternatives, Institute of Urban Studies, University of Winnipeg, 2003.

LEVINE, R. Finance and ggrowth: theory and evidence, NBER WORKING PAPER SERIES, Working Paper 10766, http://www.nber.org/papers/w10766, 2004.

LEYSHON, A. \& THRIFT, N. Financial Exclusion and the Shifting Boundaries of the Financial System. Environment and Planning A, volume 28, pages 1150-1156, 1996.

LEYSHON, A. \& THRIFT, N. Money/Space: Geographies of Monetary Transformation. London: Routledge, 1997.

LEYSHON, A. \& THRIFT, N. Geographies of financial exclusion: financial abandonment in Britain and the United States, Transaction of the Institute of British Geographers, New Serie, n. 20, p. 312-41, 1995.

MENEZES, M. S. e CROCCO, M. Moedas Locais: uma investigação exploratória sobre seus potenciais como alternativa à exclusão financeira a partir do caso do Banco Bem em Vitória/ES. Economia e Sociedade, Campinas, 2009.

RHINE, S. et al. The Role of Alternative Financial Service Providers in Serving LMI Neighbourhoods, Policy Studies, Federal Reserve Bank of Chicago, April, 2001.

RODRIGUEZ-FUENTES, C. J. Credit availability and regional development. Papers in Regional Science, v. 88, n. 1, p. $63-75,1998$.

SERVET, J. Introduction générale, em GUÉRIN, I. e SERVET, J. (eds.) Exclusion et Liens Financiers, Rapport du Centre Walras, Paris, 2004.

SINCLAR, S. Financial Exclusion: an introductory survey, Edinburgh Heriot Watt University/Center for Research into Socially Inclusive Services (CRIS), 2001. 